\title{
REVIEW AND CLASSIFICATION OF FRETTING FATIGUE TEST RIGS
}

\author{
J. De Pauw ${ }^{1}$, P. De Baets ${ }^{1}$ and W. De Waele ${ }^{1}$ \\ ${ }^{1}$ Ghent University, Laboratory Soete, Belgium
}

\begin{abstract}
There is no standard or generally accepted test rig for fretting fatigue experiments. Therefore, researchers adopt an existing concept, or build a new test rig that meets their specific requirements. However, too many different test rigs may be disadvantageous because the results of two different test rigs are hard to compare. The increasing amount of diversity is mainly caused by the lack of a recent literature survey on fretting fatigue test rigs. In 1994, Hills and Nowell described a few test rigs in Mechanics Of Fretting Fatigue. In this study, the authors made a classification of test rigs based on the contact geometry, which is determined by the test specimens, not by the test rig itself.

The authors of this article present a review of the available literature, and present a classification based on the properties of test rigs. Fretting fatigue test rigs are first divided in two categories based on the geometry of the test specimen: full scale and coupon scale test rigs. The latter are mostly used to perform research and are subdivided in categories based on increasing functionalities. This is the ability to apply a fatigue load, a constant normal force, and an alternating slip in the range of some micrometers. In time, from the fifties until now, progress has been seen in the design of fretting fatigue test rigs. More parameters can be controlled during experiments and more measuring techniques are incorporated. State of the art test rigs are classified in the last category with most functionalities, but still have imperfections. Future designers can use this article to classify their needs, or help to design a better test rig knowing the imperfections of the state of the art test rigs.
\end{abstract}

Keywords Fretting fatigue, test rig, coupon scale, full scale, classification

\section{INTRODUCTION}

Fretting fatigue occurs frequently in mechanical connection techniques such as bolted lap-joints, press fit connections, dovetail connections, splined couplings, ... Early failures of such connections can cause failure of the whole mechanical constructions. To prevent unexpected failures caused by fretting fatigue, a well-founded estimation of the lifetime is needed. Lifetime can be measured during experiments or calculated by theories that are validated by experiments.

Experiments are performed on a test rig that is capable to test fretting fatigue. However, there is no standard or generally accepted test rig to test fretting fatigue. Therefore, researchers copy literature designs, or design a custom test rig that meet their specific requirements. The proliferation of test rigs has negative consequences though. Results obtained from two different test rigs are very difficult to compare with each other. A slight difference in the compliance of the test rig has already a significant influence on the result in a fretting fatigue experiment. Next to the constructions of the test rigs, the test specimen geometry has a significant influence on the result of an experiment as well. Figure 1 shows the stress field during two experiments, only the height $h$ of the fretting bridges is changed, which is always arbitrarily chosen. The stress field in both experiments is very different as well as the contact pressure distribution. 

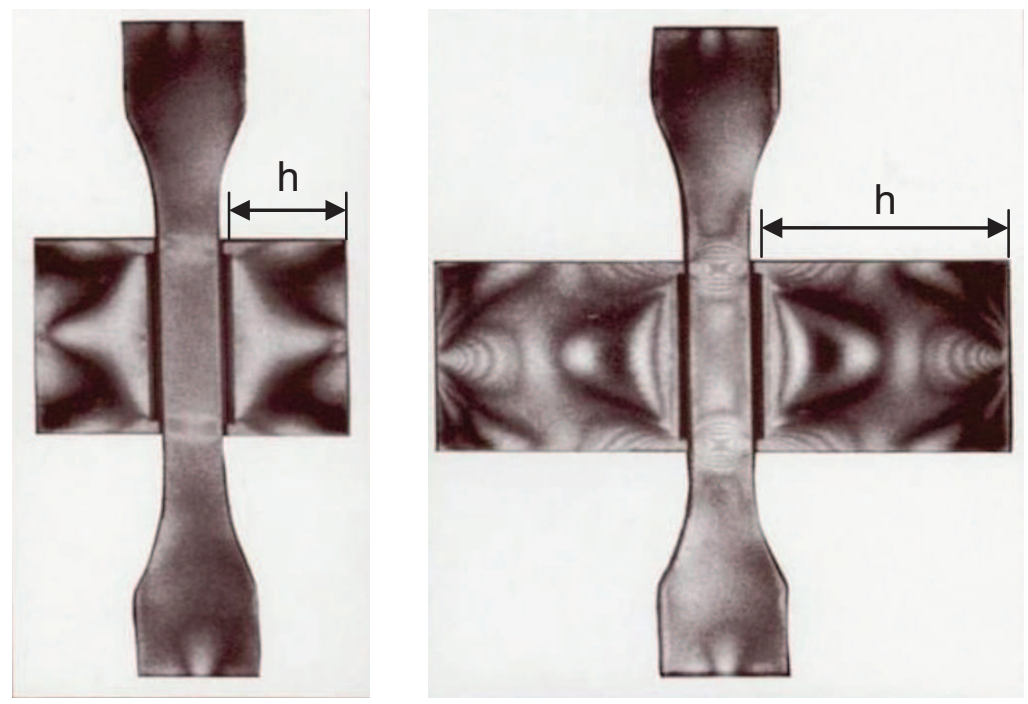

Figure 1. Photo elastic picture of the stress field, with different height $h$ of the fretting bridges [1].

Without a standard, or recent overview of existing test rigs, researchers are forced to design their own test rig, increasing the number of test rig concepts. This problem was broached in 1990 during the first conference on fretting fatigue, Standardization of fretting fatigue methods and equipment [1]. However, twenty years later there is still no standard. The best overview of fretting fatigue tests known to the authors dates from 1994 in Mechanics of fretting fatigue [2] by Hills and Nowell. However, over the last 16 years there was a progress in test rigs both qualitative and quantitative that is not yet summarized.

The authors of this article give a classification of test rigs, based solely on the properties of the test rig. This in contrast with Hills and Nowell [2] who made a classification for fretting fatigue tests based on the specimen geometry rather than the performance of test rigs.

\section{FEATURES OF A FRETTING FATIGUE TEST RIG}

Fretting fatigue in one contact point is schematically shown in Figure 2. Two specimens, a fatigue specimen (specimen) and an indenter (pad) are preloaded onto each other with a constant force $F_{N}$. The indenter is alternately moving with an amplitude $d$, the amplitude of the resulting slip $s$ is in the range of some (1..100) micrometer and fretting will occur between the pad and the specimen. Fatigue is introduced in the specimen by an alternating load $F_{\text {fat }}$.

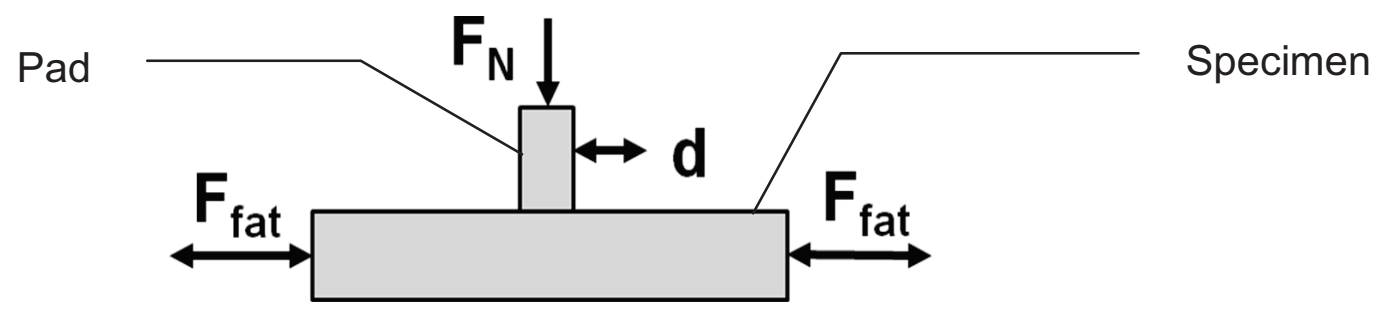

Figure 2. Schematic overview of fretting fatigue.

The schematic overview of Figure 2 describes fretting fatigue for one contact point. Most fretting fatigue experiments have multiple contact points for symmetry reasons. However, to perform a fretting fatigue experiment one needs to apply two forces and one slip in the contact area:

\section{A constant force $F_{N}$ \\ A dynamic force $F_{\text {fat }}$ \\ A relative slip $s$}


These features are not always independently controlled. For scientists who want to perform state of the art research it is interesting to control every parameter independently. If all the input parameters are known, a lot of experiments can be performed. However, industrial researchers don't know all the input parameters for this model. Therefore they perform experiments on full scale pieces and apply forces like in the real application. The interacting forces $F_{N}, F_{\text {fat }}$ and the slip $s$ in one contact area are coupled with each other by geometry, just like in the real application.

The difference between full scale experiments and coupon scale experiments is the specimen geometry. The specimens in full scale experiments are real geometries like a dovetail connection, lap joint, etc. While the geometry of the specimens in a coupon scale experiment on the other hand is not related to a real problem. The geometry focuses on the contact area where fretting fatigue initiates, as shown in Figure 2.

Different test rigs are needed to perform full scale experiments or coupon scale experiments. During coupon scale experiments we want to measure and control as much parameters as possible, preferably independent ones. In a full scale experiment however, only those forces are applied that appear in the real application.

The classification of test rigs has a first subdivision between full scale test rigs and coupon scale test rigs. The next paragraph discusses and enumerates some full scale test rigs. Paragraph 4 focuses on coupon scale test rigs, further subdivision of test rigs will be expanded in this section.

\section{FULL SCALE TEST RIGS}

Full scale test rigs are mostly used in industrial research, to estimate the lifetime of a component. The geometry of the test specimen is (scaled) related to the real application.

The advantage of a full scale test is the similarity in contact mechanics, because contact geometry and stiffness are similar. Another advantage is that only the known forces are applied. Test rigs for full scale tests usually only need one actuator, with a simple controller.

The applied force on the full scale geometry results in one or more contact points where fretting fatigue can occur. In such a contact point there is a constant force $F_{N}$, a dynamic force $F_{\text {fat }}$ and a relative slip $s$. However, these forces and slip are related to the applied force and cannot be controlled individually, nor be measured. Therefore, verification with coupon scale test is nonexistent. Even verification between two similar full scale test rigs is difficult, because the compliance of the specimens and the test rigs will determine the distribution of the normal force $F_{N}$, the fatigue force $F_{\text {fat }}$, and the relative slip $s$.

Full scale tests are more expensive than coupon scale tests, therefore full scale test are only used when economically justified, for example to predict the lifetime of connection techniques in aerospace industry. An ordinary airplane has several connection techniques that can fail due to fretting fatigue. The shell of an aircraft is constructed by aluminum sheets that are bolted or riveted together, these lap joints are sensitive to fretting fatigue [3]. In the engine of an aircraft there are two connection techniques that can fail due to fretting fatigue. A dovetail connection to connect the turbine blades onto the rotor (paragraph 3.1), and a splined connection to connect parts of the engine [4-6].

Another application where a full scale fretting fatigue test rig has been build comes from the oil and gas industry. To mine and transport oil and gas, pipelines are used. Pipelines are sometimes joined by a threaded connection that fails due to fretting fatigue [7], leading to costly repairs and expensive downtime. The aim of the full scale experiment is to determine the lifetime of such a connection accurately.

Full scale test rigs are also used to test connection techniques that are frequently used but still give problems, like press-fitted connections [8-11]. This connection technique is frequently used to connect a shaft with a bearing, a gear, a flywheel, etc. The last full scale test rig listed in this article is used to test the fretting fatigue properties of a leaf spring package that is used for cars [12].

An overview of some existing full scale test rigs is given in Table 1. This table indicates how the fatigue force $F_{\text {fat }}$, the normal force $F_{N}$, and the relative slip $s$ are applied during an experiment. Most of the full scale test rigs have only one actuator to apply the dynamic fatigue force. The slip is always dependent of the applied force and the local geometry. How the normal force is applied depends on the application. 
Table 1. Overview of how the interacting forces and slip are applied in full scale experiments

\begin{tabular}{|c|c|c|c|}
\hline & Fatigue force & Normal force & Slip \\
\hline $\begin{array}{l}\text { Dovetail } \\
\text { connection }\end{array}$ & Applied by actuator & Due to actuator & $\begin{array}{l}\text { Due to geometry and } \\
\text { fatigue force }\end{array}$ \\
\hline $\begin{array}{l}\text { Bolted or } \\
\text { riveted lap } \\
\text { connection }\end{array}$ & Applied by actuator & Pre stress bolt or rivet & $\begin{array}{l}\text { Due to geometry and } \\
\text { applied forces }\end{array}$ \\
\hline Wire rope & Applied by actuator & Pre stress by dead weight & $\begin{array}{l}\text { Due to geometry and } \\
\text { fatigue force }\end{array}$ \\
\hline $\begin{array}{l}\text { Wire rope } \\
\text { connection }\end{array}$ & Applied by actuator & Pre stress by dead weight & $\begin{array}{l}\text { Due to geometry and } \\
\text { applied force }\end{array}$ \\
\hline $\begin{array}{l}\text { Press-fit } \\
\text { connections }\end{array}$ & $\begin{array}{l}\text { Applied by electric motor } \\
\text { and geometry }\end{array}$ & Press fit geometry & $\begin{array}{l}\text { Due to geometry and } \\
\text { applied forces }\end{array}$ \\
\hline $\begin{array}{l}\text { Splined } \\
\text { coupling }\end{array}$ & Applied by actuator & Pre stress by spring system & $\begin{array}{l}\text { Due to geometry and } \\
\text { applied forces }\end{array}$ \\
\hline $\begin{array}{l}\text { Threaded } \\
\text { connections }\end{array}$ & $\begin{array}{l}\text { Applied by electric motor } \\
\text { and geometry }\end{array}$ & $\begin{array}{l}\text { Pre stress in threaded } \\
\text { connection }\end{array}$ & $\begin{array}{l}\text { Due to geometry and } \\
\text { applied forces }\end{array}$ \\
\hline Leaf spring & Applied by actuator & $\begin{array}{l}\text { Pre stress of leaf spring } \\
\text { package }\end{array}$ & $\begin{array}{l}\text { Due to geometry and } \\
\text { applied forces }\end{array}$ \\
\hline
\end{tabular}

The next two paragraphs give more details about two full scale test rigs. The first test rig is used to test dovetail connections, a typical connection technique in aircraft engines, steam turbines and other turbines. The second test rig is developed to test wire ropes that are used as overhead conductors.

\subsection{Dovetail connections}

Modern aircraft engines (turboprop) are based on a turbo machine, fluid energy is converted into mechanical energy by means of a blade. The blade transfers the energy onto the rotor through a dovetail connection. Due to the wedge-formed shape of the dovetail and the interacting forces on the blade, a slip arises between the blade and the rotor [13-15].

A full scale experiment of a dovetail connection is shown in Figure 3 . The specimens have the shape of a dovetail connection. The only force that is applied during the experiment is $F$, working in vertical direction. There are two contact areas between the blade and the rotor, notice that this test rig has replaceable parts in the upper block. The dovetail connection is failed due to fretting fatigue, a crack initiated in the contact area, and propagated through the specimen (crack in Figure 3).

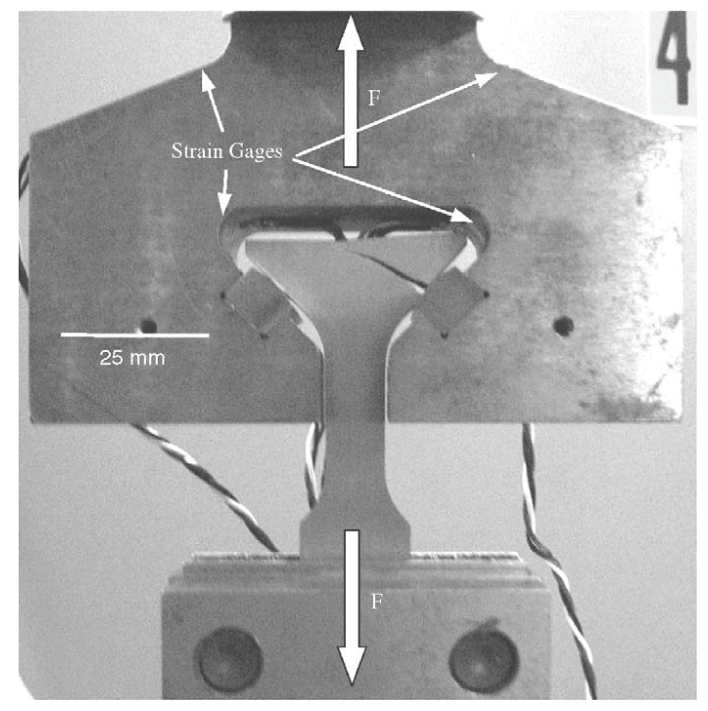

Figure 3. Dovetail fretting fatigue experimental setup with failed specimen [14]. 


\subsection{Wire rope and wire rope fixture}

The second full scale test rig discussed in this paper is developed to test an overhead conductor. Overhead conductors are just wire ropes that transport electricity. This test rig can be used to test other applications of wire ropes like a hoisting mechanism, a suspended bridge, a ski lift, etc.

The test rig exists of a 42 meter prestressed wire rope that is subjected to a dynamic loading by the shaker. The small wires in the wire rope will slip over each other leading to fretting fatigue failure in the wire rope. This problem can occur in the whole wire rope. However, most problems with fretting fatigue are seen in the suspension points of the wire rope. Clamping fixtures are placed around the wire rope and are securely tightened. The larger dimensions of the clamping fixture leads to a stiffer entity than the wire rope (Figure 5 left). This results in a discontinuity of the bending stiffness of the wire rope in the vicinity of such a fixture, and will result in fretting fatigue.

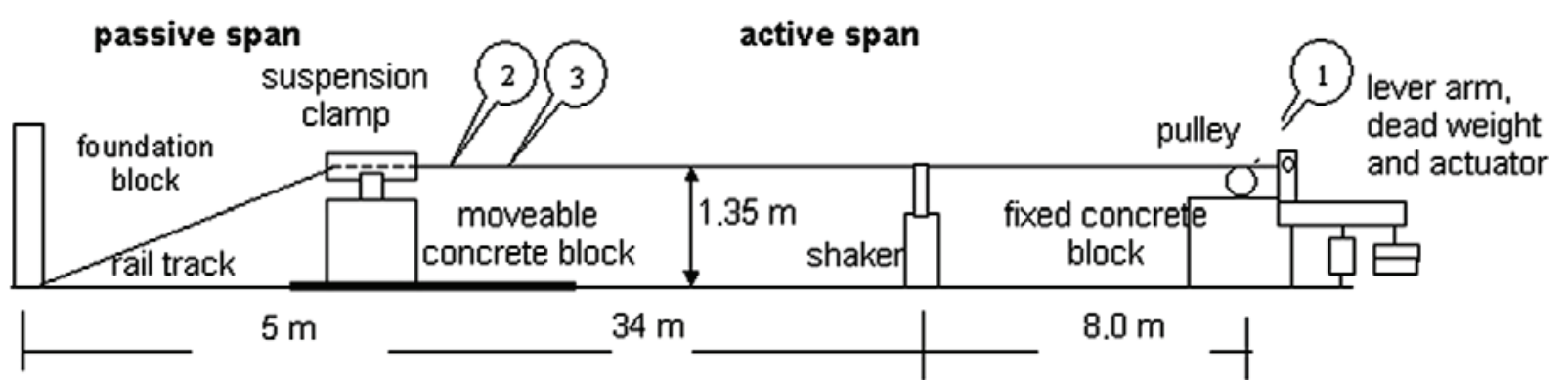

Figure 4. Schematic view of the fretting fatigue test rig for overhead conductors [16].

A heavily worn wire rope is shows in Figure 5 right. The outer layer of wires are worn and broken due to fretting fatigue between the wire rope and the clamping fixture. The underlying layer of wires is visible and shows elliptical wear marks due to fretting between two wires (trellis contact). Some of these wires are broken in the worn contact due to fretting fatigue (not visible on Figure 5).
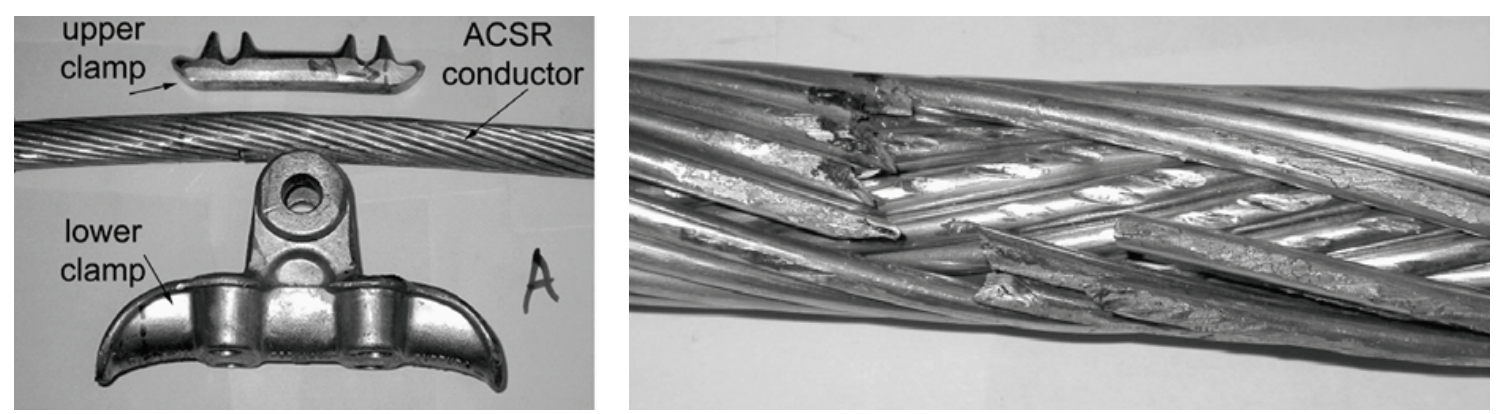

Figure 5. Clamping fixture not mounted on the wire rope (left) and a heavily worn wire rope (right) [16].

\section{COUPON SCALE TEST RIGS}

In contradiction to a full scale test rig, the specimens of a coupon scale test rig have no similarity with the real geometry of an application. Coupon scale testing is a common practice for material characterization and is used by academics to perform research.

Simple geometry specimens are ideal for material characterization tests regarding to fretting fatigue. It is assumed that all the specimens are manufactured and assembled equally, so the interacting forces in the vicinity of the contact area are the same. A second assumption is even more doubtful: when one has a ranking for materials on coupon scale it is assumed tacitly that an identical ranking applies to the real problem [2].

Academic researchers adopted the coupon scale technique for state of the art research. Coupon scale specimens have the advantage that all the dimensions can be chosen arbitrarily by the designer. Manageable specimens for laboratory testing have their benefits. However, the major advantage of a coupon specimen is the convenience to perform a parametric study on the dimensions of the specimen. 
A well designed test rig has similar ease to perform parametric studies. Progress can be seen over time, the first types of coupon scale test rigs consist of one servo-hydraulic actuator and some screws to apply the forces. While most modern test rigs have multiple actuators to control the forces and slip independently in time.

The last advantage of coupon scale test rigs that will be cited here is the visibility of the contact. In most full scale test rigs it is impossible to see the contact area, nor the crack. For research however it is important to know the slip between pad and specimen and is it interesting to see the surface where cracks will occur. Crack propagation, and possible crack initiation, can then be studied with new field measuring techniques such as a thermal camera [17-19], an optical camera [20-22], a magnetic camera [23]...

\subsection{One actuator test rig}

This section discusses test rigs that have one controllable actuator. This can be a hydraulic actuator, a piezo-electric shaker, any crank mechanism or other controllable drive unit. The bulk fatigue load $F_{\text {fat }}$ is controlled by this actuator, all other applied external forces are set manually.

The normal force is mostly applied by a floating circular spring system, called a proving ring (Figure 6 ). The proving ring operates like a pre-stressed spring whereby the initial force is set by a setscrew and works based on the compliance of the spring. If the total length of the compressed parts doesn't change, the normal force stays constant during the experiment. This is not the case in fretting (fatigue) experiments, where fretting causes wear.

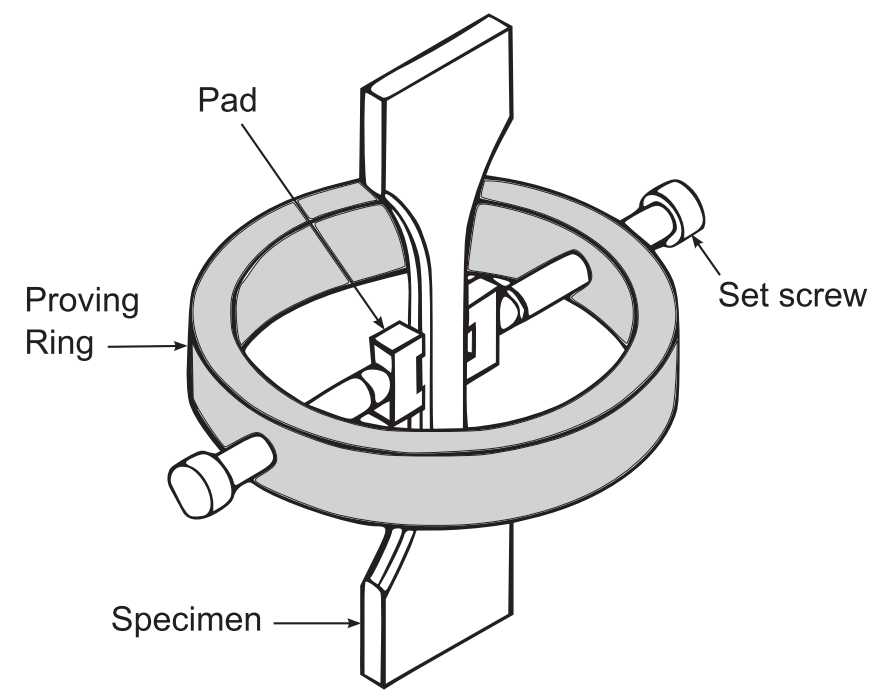

Figure 6. Fretting fatigue experiment whereby the normal load is applied with a proving ring [24]

If voluminous oxidized wear particles stay in the contact area they will cause an elongation of the compressed parts, and the proving ring. This results in a higher normal force $F_{N}$ from the proving ring. On the other hand if particles escape from the contact area the pads will move towards the specimen due to wear. This is a shortening of the loading train that results in a decrease of normal force $F_{N}$. These mechanisms are undesirable if the normal force has to be constant. For example, R.B. Waterhouse used a proving ring with an unidirectional stiffness of about $12 \mathrm{MN} / \mathrm{mm}$, this resulted in a reduction of $15.5 \mathrm{MPa}$ when the relative distance of the two surfaces decreases $25 \mu \mathrm{m}$ [25].

Besides the fatigue force and the normal force, one should also apply a slip between the specimen and the pad. The relative displacement between the fatigue specimen and the pad is realized by the compliance of the specimens (fatigue specimen and pad) and the compliance of the test rig. The slip is always in phase with the fatigue loading and cannot be controlled independently. Two types of pad geometries will be discussed: floating fretting bridges (paragraph 3.1.1) and fixed fretting bridges (paragraph 3.1.2) as shown in Figure 7. 
(a)

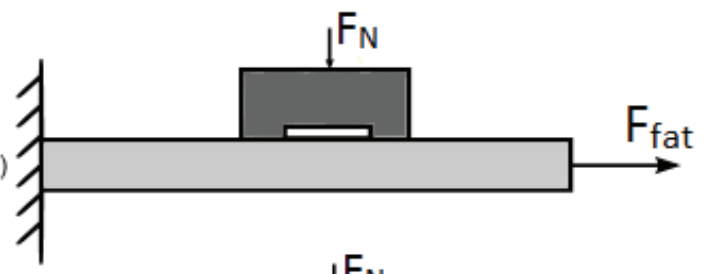

(b)

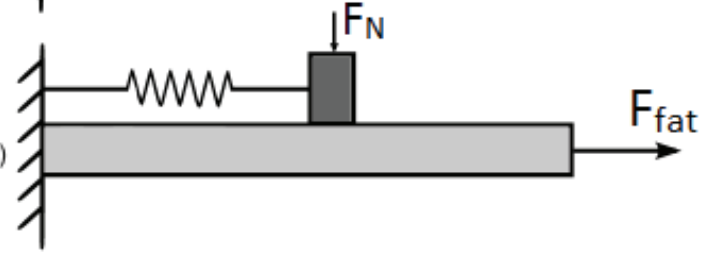

Figure 7. Floating fretting bridge (a) and Fixed fretting bridge (b).

\subsubsection{Floating fretting bridges}

A floating fretting bridge is a pad that has two contact points with the specimen (Figure 7a). During an experiment two floating fretting bridges are mounted on one fatigue specimen for symmetry. Floating fretting bridges in combination with a proving ring (Figure 6) are frequently used because of their easy installation on an ordinary universal load frame.

Applying a fatigue load on the specimen will elongate the specimen. The initial contact points of one floating fretting bridge move apart, and a slip will occur in both contact points. The slip is in phase with the applied fatigue force, and cannot be controlled. The slip can be influenced prior to an experiment by adapting the geometry of the floating fretting bridges or the specimen. However, not all combinations of slip and fatigue load are possible.

Disadvantage of floating fretting bridges is the difficulty to compare results. A change in the geometry of the floating fretting bridges gives significant different results (see Figure 1). Other disadvantages of floating fretting bridges are the impossibility to measure the slip and the tangential force.

\subsubsection{Fixed fretting bridges}

A fixed fretting bridge is fixed on the test rig, and has only one contact point with the fatigue specimen (Figure 7b). During an experiment two fixed fretting bridges are mounted on one fatigue specimen (Figure 8). Loading the specimen causes a displacement of the contact area. A slip will occur between the pad and the specimen. This slip is in phase with the applied fatigue force.

In contradiction to floating fretting bridges, fixed fretting bridges have the ability to measure the slip and the tangential force. The tangential force can be measured by strain gauges on the fixed fretting bridge which act as a calibrated spring [26]. 


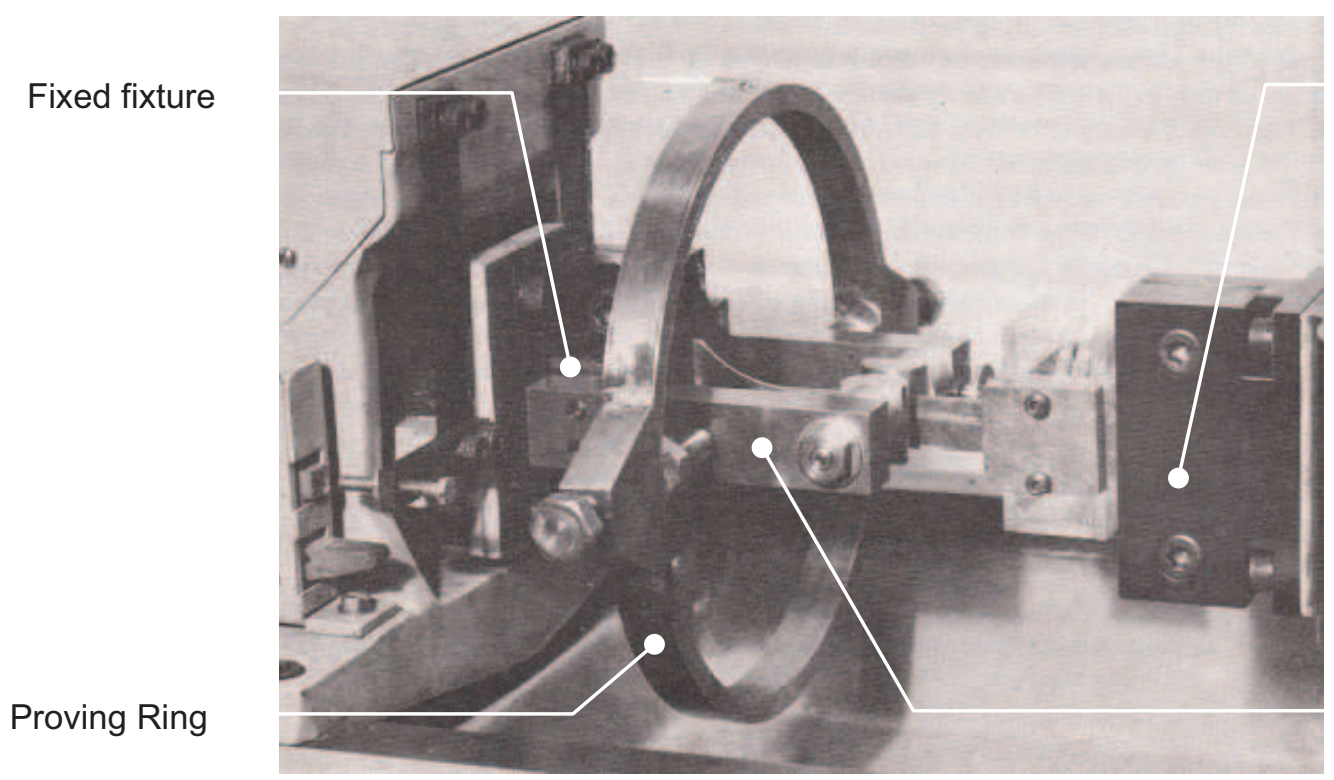

Moving fixture

Fixed fretting bridge

Figure 8. Fretting fatigue test rig with half fretting bridges and proving ring [25].

\subsection{One actuator test rig with adjustable compliance}

A second type of coupon scale test rigs is based on one actuator, and has the ability to adjust the compliance of the test rig. The working principle is similar to fixed fretting bridges, Figure $7 \mathrm{~b}$. The only difference is that these test rig are designed to have an (continuous) adjustable compliance. This allows more combinations of slip and fatigue load. The slip is in phase with the fatigue load, but can be influenced prior to an experiment by adjusting the compliance of the test rig.

The mechanisms to adjust the compliance of the test rig are based on longitudinal springs [27] or cantilever beams [28-30]. A schematic drawing of the latter is shown in Figure 9. Two fretting pads are mounted on a stiff plate by linear bearings and load cells (LC4-LC7). The stiff plate is connected onto the rigid base by two cantilever beams. The support of the cantilever beams can be adjusted, so the stiffness of the test rig can be adjusted continuously prior to an experiment.

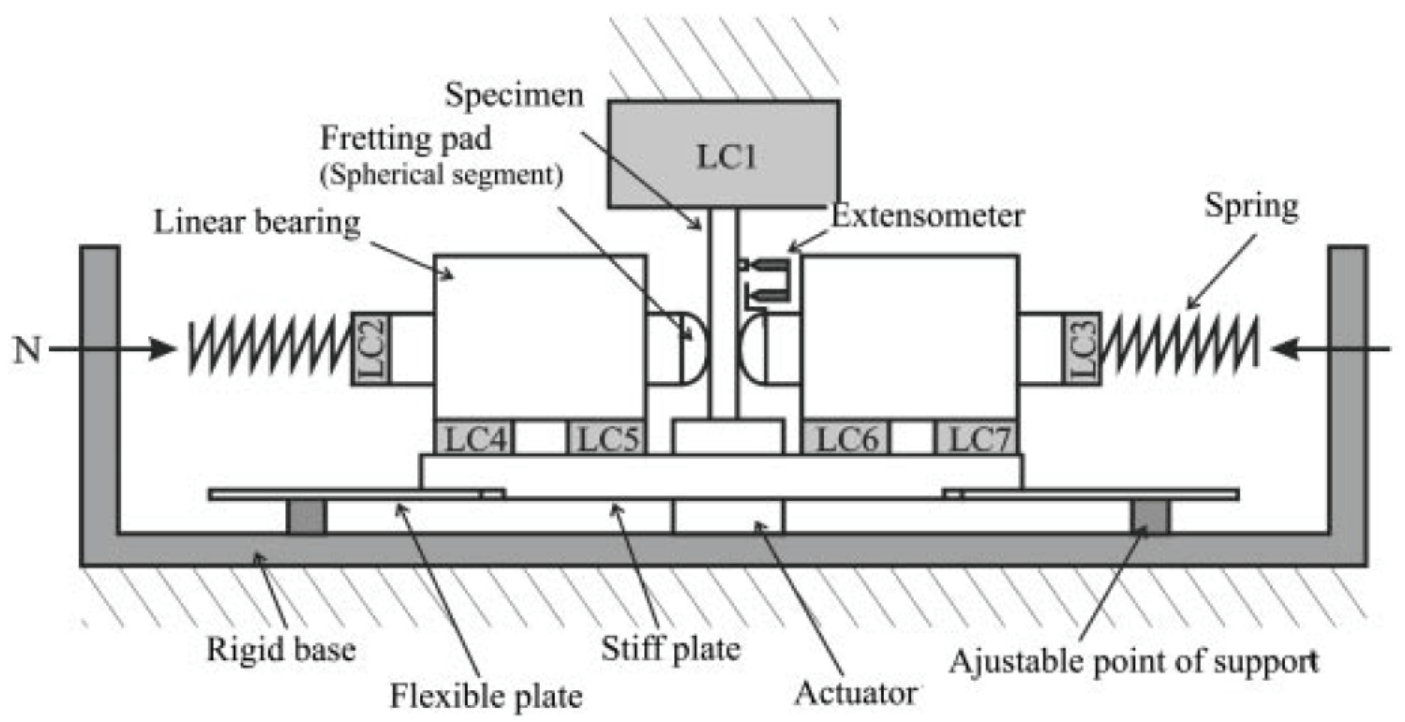

Figure 9. Fretting fatigue test rig with adjustable compliance, adjustable by support [30]. 


\subsection{Two actuators test rig}

The last type of fretting fatigue test rig that will be discussed in this paper is based on two actuators that independently control the fretting action and the fatigue action during experiments. In previously discussed test rigs these actions where always coupled by geometry and (adjustable) compliance of the test rig.

This type of test rig is first used by researchers at the University of Oxford [31] to investigate the influence of the fretting action and the fatigue action separately. Therefore the authors used a test rig whereby the fretting and fatigue action can be controlled independently. A schematic overview is shown in Figure 10 for one contact point.

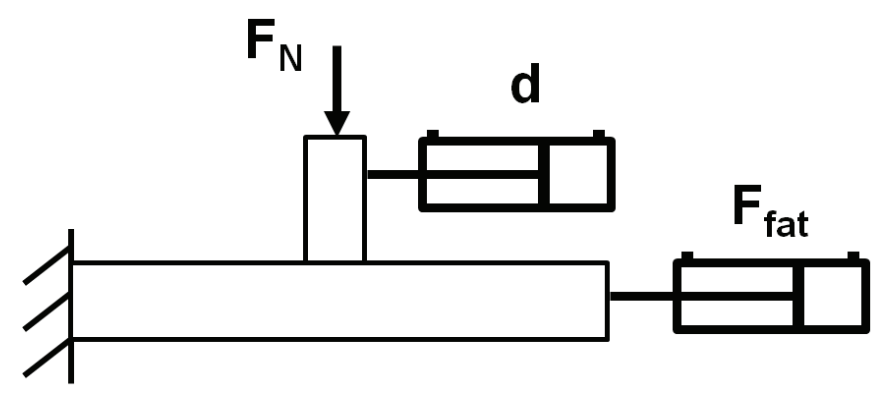

Figure 10. Schematic view of a fretting fatigue test rig with two actuators

A schematic view of a real test rig is shown in Figure 11. Two pads are used for symmetry reasons, and are installed on a fretting fixture (5). This fretting fixture is connected to a hydraulic actuator (1) by means of a structural frame (3). The fretting fixture is moved to control the slip between the pad and the specimen. However, the displacement of the fixture will depend on the displacement of the hydraulic actuator and the compliance of the structural frame. This compliance will ensure that the slip cannot be controlled accurately. The only literature that mentions the accuracy of the slip that they can apply is Magadu et. al. [32], who are able to control the slip in the range of $15 \mu \mathrm{m}$.

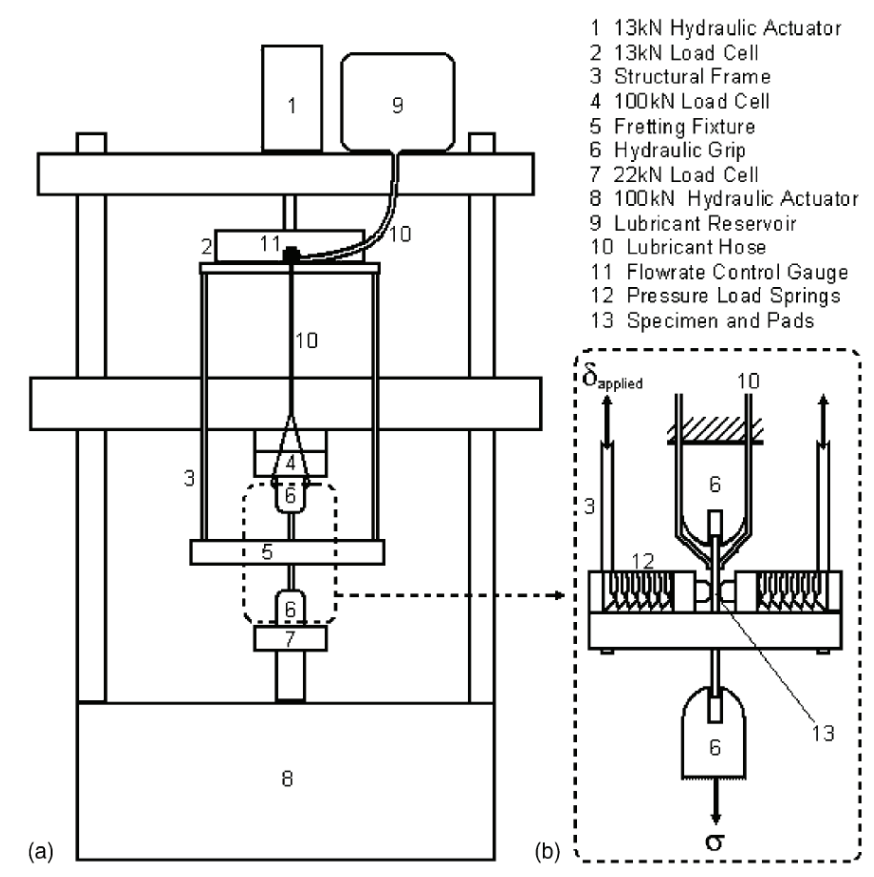

Figure 11. Schematic view of the test rig at Wright-Patterson AFB [33]

Table 2 gives an overview of five existing two actuators test rigs that are known to the authors, and lists the driving equipment for the fatigue force, normal force and slip. All the test rigs use a hydraulic actuator to apply the fatigue force. The slip in the test rigs is applied by a second hydraulic actuator. The difference between the listed test rigs is how the normal load is applied. 
Table 2. Overview of some fretting fatigue test rigs based on two actuators

\begin{tabular}{llll}
\hline $\begin{array}{l}\text { Research } \\
\text { institute }\end{array}$ & Fatigue force & Normal force & Slip \\
\hline $\begin{array}{l}\text { Wright- } \\
\text { Patterson AFB }\end{array}$ & Hydraulic actuator & Compliant springs & $\begin{array}{l}\text { Hydraulic actuator and } \\
\text { compliance test rig }\end{array}$ \\
$\begin{array}{l}\text { University of } \\
\text { Brasília }\end{array}$ & Hydraulic actuator & Hydraulic accumulator & $\begin{array}{l}\text { Hydraulic actuator and } \\
\text { compliance test rig }\end{array}$ \\
$\begin{array}{l}\text { University of } \\
\text { Oxford }\end{array}$ & Hydraulic actuator & Hydraulic actuator & $\begin{array}{l}\text { Hydraulic actuator and } \\
\text { compliance test rig }\end{array}$ \\
$\begin{array}{l}\text { United } \\
\text { Technologies } \\
\text { Research Center } \\
\begin{array}{l}\text { University of } \\
\text { Lyon }\end{array}\end{array}$ & Hydraulic actuator & Hydraulic actuator & $\begin{array}{l}\text { Hydraulic actuator and } \\
\text { compliance test rig }\end{array}$ \\
\hline
\end{tabular}

\section{CONCLUSION}

A classification of fretting fatigue test rigs based on the properties of the test rigs is given in Figure 12. A first difference of test rigs is based on the specimens scale, full scale or coupon scale. Full scale test rigs are directly related to a real application, eight full scale rigs are listed in Table 1.

Further classification has been done for the coupon scale test rigs. Based on their capability to apply a slip $s$, tree categories are made. The first type, one actuator test rig, is not designed to control or influence the slip. The second type, one actuator test rig with adjustable compliance, can influence the slip in advance, but is not able to control the slip during the experiments. In both types of test rig, the slip is in phase with the fatigue force. The third and last type of coupon scale test rigs, two actuator test rig, can control the slip independently of the fatigue load. However, due to construction of the test rig, the slip cannot be applied accurately in the range of some micrometer, which is necessary to test fretting.

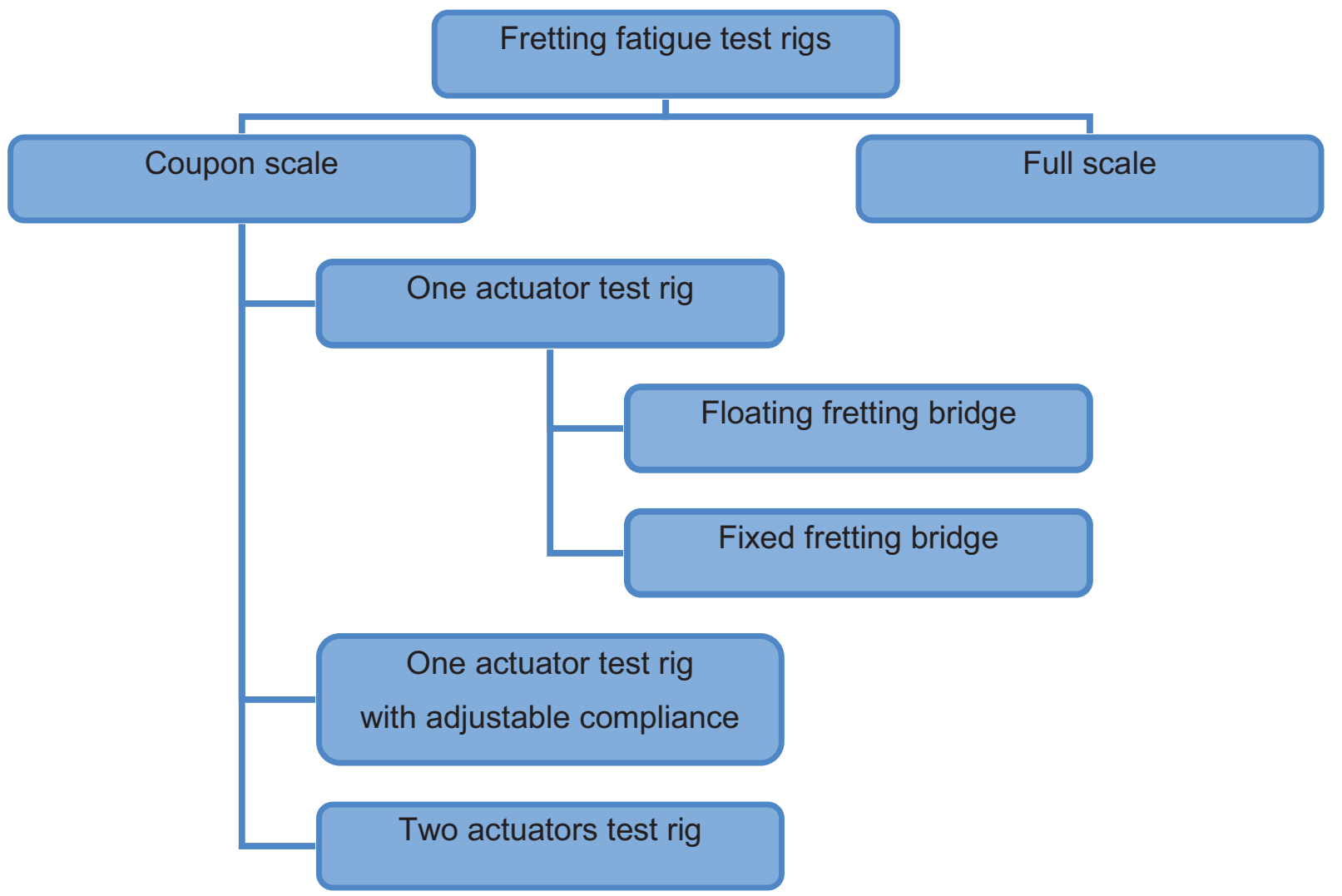

Figure 12. Classification of fretting fatigue test rigs. 


\section{NOMENCLATURE}

$\begin{array}{lll}\text { d } & \text { relative movement of pad } & \mu \mathrm{m} \\ \mathrm{s} & \text { slip } & \mu \mathrm{m} \\ \mathrm{h} & \text { height fretting bridge } & \mathrm{mm} \\ \mathrm{F}_{\mathrm{N}} & \text { normal force } & \mathrm{N} \\ \mathrm{F}_{\text {fat }} & \text { fatigue force } & \mathrm{N} \\ \mathrm{F} & \text { force } & \mathrm{N}\end{array}$

\section{ACKNOWLEDGEMENTS}

The authors would like to acknowledge the support of the IWT (Agency for Innovation by Science and Technology $-\mathrm{n}^{\circ}$ SB-091510)

\section{REFERENCES}

[1] M. H. Attia and R. B. Waterhouse, Standardization of fretting fatigue test methods and equipment, 1992.

[2] D. A. Hills and D. Nowell, Mechanics of fretting fatigue vol. 30, 1994.

[3] S. Wagle and $\mathrm{H}$. Kato, "Ultrasonic wave intensity reflected from fretting fatigue cracks at bolt joints of aluminum alloy plates," Ndt \& E International, vol. 42, pp. 690-695, Dec 2009.

[4] D. Houghton, P. M. Wavish, E. J. Williams, and S. B. Leen, "Multiaxial fretting fatigue testing and prediction for splined couplings," International Journal of Fatigue, vol. 31, pp. 1805-1815, Nov-Dec 2009.

[5] T. R. Hyde, S. B. Leen, and I. R. McColl, "A simplified fretting test methodology for complex shaft couplings," Fatigue \& Fracture of Engineering Materials \& Structures, vol. 28, pp. 1047-1067, Nov 2005.

[6] S. B. Leen, T. H. Hyde, C. H. H. Ratsimba, E. J. Williams, and I. R. McColl, "An investigation of the fatigue and fretting performance of a representative aero-engine spline coupling," Journal of Strain Analysis for Engineering Design, vol. 37, pp. 565-583, Nov 2002.

[7] L. Bertini, M. Beghini, C. Santus, and A. Baryshnikov, "Resonant test rigs for fatigue full scale testing of oil drill string connections," International Journal of Fatigue, vol. 30, pp. 978-988, 2008.

[8] B. Alfredsson, "Fretting fatigue of a shrink-fit pin subjected to rotating bending: Experiments and simulations," International Journal of Fatigue, vol. 31, pp. 1559-1570, 2009.

[9] R. Gutkin and B. Alfredsson, "Growth of fretting fatigue cracks in a shrink-fitted joint subjected to rotating bending," Engineering Failure Analysis, vol. 15, pp. 582-596, 2008.

[10] T. Juuma, "Torsional fretting fatigue strength of a shrink-fitted shaft with a grooved hub," Tribology International, vol. 33, pp. 537-543, 2000.

[11] D. H. Lee, S. J. Kwon, Y. S. Ham, and W. H. You, "Characterization of fretting damage in a pressfitted shaft below the fretting fatigue limit," in Fatigue 2010. vol. 2, P. Lukas, Ed. Amsterdam: Elsevier Science Bv, pp. 1945-1949.

[12] M. L. Aggarwal, R. A. Khan, and V. P. Agrawal, "Effect of surface roughness on the fretting fatigue behaviour of EN45A spring steel," in Proceedings of the Institution of Mechanical Engineers -- Part B -- Engineering Manufacture. vol. 220: Professional Engineering Publishing, 2006, pp. 1325-1331.

[13] P. J. Golden and T. Nicholas, "The effect of angle on dovetail fretting experiments in Ti-6Al-4V," Fatigue \& Fracture of Engineering Materials \& Structures, vol. 28, pp. 1169-1175, Dec 2005.

[14] P. J. Golden and J. R. Calcaterra, "A fracture mechanics life prediction methodology applied to dovetail fretting," Tribology International, vol. 39, pp. 1172-1180, Oct 2006.

[15] A. Kermanpur, H. S. Amin, S. Ziaei-Rad, N. Nourbakhshnia, and M. Mosaddeghfar, "Failure analysis of Ti6Al4V gas turbine compressor blades," Engineering Failure Analysis, vol. 15, pp. 1052-1064, Dec 2008.

[16] C. R. F. Azevedo, A. M. D. Henriques, A. R. Pulino Filho, J. L. A. Ferreira, and J. A. Araújo, "Fretting fatigue in overhead conductors: Rig design and failure analysis of a Grosbeak aluminium cable steel reinforced conductor," Engineering Failure Analysis, vol. 16, pp. 136-151, 2009.

[17] O. Plekhov, T. Pain-Luc, N. Saintier, S. Uvarov, and O. Naimark, "Fatigue crack initiation and growth in a $35 \mathrm{CrMo} 4$ steel investigated by infrared thermography," Fatigue \& Fracture of Engineering Materials \& Structures, vol. 28, pp. 169-178, Jan 2005.

[18] D. Wagner, N. Ranc, C. Bathias, and P. C. Paris, "Fatigue crack initiation detection by an infrared thermography method," Fatigue \& Fracture of Engineering Materials \& Structures, vol. 33, pp. 12-21, Jan 2009. 
[19] W. Thomson, "On the dynamical theory of heat - with numerical results deduced from Mr.Joule's equivalent of a thermal unit and M. Regaut's observations on steam," Royal Society of Edinburgh, Transactions of the Royal Society, pp. 261-288, 1853.

[20] S. Henkel, D. Holländer, M. Wünsche, H. Theilig, P. Hübner, H. Biermann, and S. Mehringer, "Crack observation methods, their application and simulation of curved fatigue crack growth," Engineering Fracture Mechanics, vol. 77, pp. 2077-2090.

[21] B. Bruzek and E. Leidich, "Evaluation of crack growth at the weld interface between bronze and steel," International Journal of Fatigue, vol. 29, pp. 1827-1831, 2007/11//.

[22] P. Cavaliere, A. D. Santis, F. Panella, and A. Squillace, "Thermoelasticity and CCD analysis of crack propagation in AA6082 friction stir welded joints," International Journal of Fatigue, vol. 31, pp. 385392, 2009.

[23] J. Hwang, J. Lee, and S. Kwon, "The application of a differential-type Hall sensors array to the nondestructive testing of express train wheels," NDT \& E International, vol. 42, pp. 34-41, 2009.

[24] K. K. Liu and M. R. Hill, "The effects of laser peening and shot peening on fretting fatigue in Ti-6Al-4V coupons," Tribology International, vol. 42, pp. 1250-1262, 2009.

[25] R.B.Waterhouse, Fretting Corrosion. Oxford: Pergamon Press 1972.

[26] K. Endo and H. Goto, "Initiation and propagation of fretting fatigue cracks," Wear, vol. 38, pp. 311324, 1976.

[27] R. Cortez, S. Mall, and J. R. Calcaterra, "Investigation of variable amplitude loading on fretting fatigue behavior of Ti-6Al-V," International Journal of Fatigue, vol. 21, pp. 709-717, Aug 1999.

[28] S. Fouvry, K. Kubiak, A. M. Marechal, and J. M. Vernet, "Behaviour of shot peening combined with WC-Co HVOF coating under complex fretting wear and fretting fatigue loading conditions," Surface \& Coatings Technology, vol. 201, pp. 4323-4328, 20 December 2006.

[29] M. C. Gean and T. N. Farris, "Elevated temperature fretting fatigue of Ti-17 with surface treatments," Tribology International, vol. 42, pp. 1340-1345, Sep 2009.

[30] Wittkowsky, Birch, Dominguez, and Suresh, "An apparatus for quantitative fretting testing," Fatigue \& Fracture of Engineering Materials \& Structures, vol. 22, pp. 307-320, 1999.

[31] L. J. Fellows, D. Nowell, and D. A. Hills, "On the initiation of fretting fatigue cracks," Wear, vol. 205, pp. 120-129, 1997.

[32] A. Mugadu, D. A. Hills, and D. Nowell, "Modifications to a fretting-fatigue testing apparatus based upon an analysis of contact stresses at complete and nearly complete contacts," Wear, vol. 252, pp. 475-483, 2002.

[33] R. Magaziner, O. Jin, and S. Mall, "Slip regime explanation of observed size effects in fretting," Wear, vol. 257, pp. 190-197, 2004. 